\title{
SHORT- AND LONG-TERM EFFECTS OF A SINGLE INJECTION OF DEPO-MEDROXYPROGESTERONE ACETATE (PROVERA) ON THE VAGINAL SMEAR, OVULATION AND MATING IN THE RAT
}

\author{
Z. DICKMANN \\ Department of Gynecology and Obstetrics, \\ University of Kansas Medical Center, \\ Kansas City, Kansas 66103, U.S.A.
}

(Received 9th February 1972)

\begin{abstract}
Summary. In rats injected with depo-medroxyprogesterone acetate (depo-MPA) at either 10.00 or 22.00 hours on the last day of dioestrus, the anticipated ovulation was blocked; injection at 10.00 hours on the day of pro-oestrus did not block ovulation. When ovulation was blocked, there followed a dioestrous period which lasted, on average, $72.3 \pm 1.9$ days. Following the prolonged dioestrus, the lengths of the initial cycles were irregular. In most cases, mating did not occur during the first oestrous period. When mating eventually occurred, it was fertile yielding normal offspring. In principle, the results are similar to those obtained for women injected with depo-MPA to effect contraception.
\end{abstract}

\section{INTRODUCTION}

In the rat, a single injection of medroxyprogesterone acetate (MPA) in oil, administered between 09.00 and 12.00 hours on the last day of dioestrus, blocked the ovulation anticipated some $40 \mathrm{hr}$ later (Banik \& Herr, 1969; Banik, Haltrecht \& Herr, 1970). In the present study, the short and longterm effects of a single injection of depo-MPA (in an aqueous suspension) were investigated. Answers were sought to the following questions: (1) in order to block ovulation, how long before the endogenous release of $\mathbf{L H}$ should MPA be injected? (2) when MPA is injected too late to block ovulation, does mating occur, and if so, are the ovulated eggs fertilized? (3) how long is the dioestrous period in MPA-injected rats with blocked ovulation? (4) after the termination of a prolonged MPA-induced dioestrous period, are the cycles regular, and do females permit mating during the first oestrous period? (5) when mating eventually occurs, is it fertile?

\section{MATERIALS AND METHODS}

The rats used were young, adult, virgin females of the Holtzman strain, weighing 180 to $240 \mathrm{~g}$, and housed in air-conditioned quarters in which the 
lights were on from 05.00 to 19.00 hours. Vaginal smears were recorded for at least two cycles before a female was assigned to an experiment. The length of the majority of the cycles was 5 days. Females with irregular cycles were not used. Throughout the experiments, vaginal smears were recorded daily between 08.00 and 10.00 hours. The designations of the smears were: oestrus' $\mathrm{C}$ ' (predominantly cornified cells); dioestrus-' $\mathrm{L}$ ' (predominantly leucocytes); and pro-oestrus-' $N$ ' (predominantly nucleated cells) or 'N/C' (a mixture of nucleated and cornified cells). Each rat was injected with an aqueous suspension of $12.5 \mathrm{mg}$ depo-MPA ( $6 \alpha$-methyl-17 $\alpha$-hydroxyprogesterone acetate) (Upjohn), $3.125 \mathrm{mg}$ depo-MPA/0.5 ml of $0.9 \% \mathrm{NaCl}$ solution being injected into each of four subcutaneous sites. Further details of the various experimental procedures are given in the 'Results' section.

\section{RESULTS}

The results of Exps 1, 2 and 3 are summarized in Table 1; the results of Exp. 4 are recorded in Table 2.

\section{Experiment 1}

At 10.00 hours on the last day of dioestrus (i.e. the day preceding the anticipated day of pro-oestrus), the rats were injected with MPA. In the afternoon of the following day (Day 0), they were caged overnight with males of proven fertility. The next morning, the females were checked for vaginal plug and/or spermatozoa in the vagina. This day was designated Day 1 regardless of whether or not mating had occurred. On Day 2, between 09.00 and 11.00 hours, the rats were killed. The oviducts were then excised and flushed with $0.9 \% \mathrm{NaCl}$ solution to determine whether ovulation had occurred and, if so, whether the eggs were fertilized.

Table 1. Effects of injecting depo-MPA at different times of the cycle on mating and ovulation in rats

\begin{tabular}{c|c|c|c|c|c|c}
\hline \multirow{2}{*}{$\begin{array}{c}\text { Exp. } \\
\text { no. }\end{array}$} & $\begin{array}{c}\text { No. of } \\
\text { rats }\end{array}$ & \multicolumn{2}{|c|}{ MPA injected } & \multicolumn{2}{|c|}{ No. of rats } & Day* \\
\cline { 3 - 5 } & hours & Mating & Ovulating & $\begin{array}{c}\text { Total no. of } \\
\text { eggs ovulated }\end{array}$ \\
\hline 1 & 12 & $(-1)$ & 10.00 & 0 & 3 & 8 \\
2 & 15 & $(-1)$ & 22.00 & 0 & 1 & 6 \\
3 & 12 & 0 & 10.00 & 12 & 12 & 97 \\
\hline
\end{tabular}

* Day $(-1)=$ last day of dioestrus; Day $0=$ day of pro-oestrus.

On Day 0 , all rats had a pro-oestrous smear, as would have occurred without treatment. However, on Day 1, the smear was L; it would have been C, had the rats not been treated. None of the rats mated. Nine rats did not ovulate; the remaining three ovulated one, two and five eggs, respectively.

\section{Experiment 2}

The procedures were the same as in Exp. 1, but MPA was injected at 22.00 hours instead of at 10.00 hours. The results were similar to those of Exp. 1. 
On Day 0, thirteen rats had a pro-oestrous smear whereas two rats had a dioestrous smear. On Day 1 , the smear was $L$ in all the rats. None of the rats mated. Fourteen rats did not ovulate, whereas one rat ovulated six eggs.

\section{Experiment 3}

The procedures were the same as in Exp. 1, but MPA was injected at 10.00 hours on Day 0 (the day of pro-oestrus). All the twelve rats mated and ovulated. The mean number of eggs ovulated was $8 \cdot 0 \pm 0 \cdot 8$. The total yield of eggs was ninety-seven: eighty-five $(88 \%)$ two-cell; eight $(8 \%)$ one-cell; and four $(4 \%)$ degenerated eggs. All the eggs were penetrated by spermatozoa except for three of the degenerated eggs. Ovulation and fertilization were, therefore, within normal range. The vaginal smears did not deviate from the normal, i.e. they were $\mathrm{C}$ on Day 1.

Table 2. The number of consecutive days of $\mathrm{L}$ smears in rats following injection of MPA, lengths of cycles from termination of the prolonged dioestrous period until mating occurred, and the oestrous period when mating occurred

\begin{tabular}{c|c|c|c}
\hline $\begin{array}{c}\text { Rat } \\
\text { no. }\end{array}$ & $\begin{array}{c}\text { No. of days } \\
\text { of } L \text { smears }\end{array}$ & $\begin{array}{c}\text { Length of } \\
\text { cycles (days) }\end{array}$ & $\begin{array}{c}\text { Oestrous period } \\
\text { when } \\
\text { mating occurred }\end{array}$ \\
\hline 1 & 61 & 4 & 2nd \\
2 & 73 & 4 & 2nd \\
3 & 71 & 4 & 2nd \\
4 & 68 & 4 & 2nd \\
5 & 67 & - & 1st \\
6 & 76 & - & 1st \\
7 & 75 & 14 & 2nd \\
8 & 65 & $5,3,3$ & 2nd \\
9 & 70 & 5 th \\
10 & 83 & 10,4 & 2nd \\
11 & 81 & $5,4,12,9$ & 3rd \\
12 & 73 & $2,2,5$ & 4th \\
13 & 87 & $4,4,4$ & 4th \\
14 & 60 & $13,17,4$ & 4th \\
15 & 75 & & \\
\hline
\end{tabular}

\section{Experiment 4}

At 10.00 hours on the last day of dioestrus, rats were injected with MPA (as in Exp. 1). Daily vaginal smears were then recorded to determine for how many days the females remained in dioestrus. It was assumed that as long as the L smear persisted, the rat did not ovulate. When eventually the females exhibited a pro-oestrous smear, they were caged overnight with males. If mating did not occur, the recording of daily vaginal smears was continued until the next pro-oestrous period when the females were again placed with males. This procedure was repeated until mating occurred. Pregnant females were allowed to proceed to term; the litter size and sex of the young were recorded. The young were raised and, when adults, their capacity to reproduce was tested.

On Day 1, all the fifteen rats used had an L smear which persisted for 60 to 
87 days, with a mean of $72.3 \pm 1.9$ days. After the prolonged dioestrous period, mating occurred at the first (two rats), second (seven rats), third (one rat), fourth (four rats) and fifth (one rat) oestrous periods. The lengths of the cycles after the prolonged dioestrus varied (see Table 2) and, in most cases, was not 5 days - the predominant cycle length before treatment. The length of the gestation period (22 to 23 days) and the litter size (10.3 \pm 0.7 young) were within normal range. The sex ratio of the newborn was $1: 1$. The young of both sexes grew up to become normal adults capable of reproducing.

\section{DISGUSSION}

The results of Exp. 1 confirmed the findings of Banik \& Herr (1969) and Banik et al. (1970), showing that injecting MPA at 10.00 hours on the last day of dioestrus blocked the anticipated ovulation. It is assumed that the ovulatory block resulted from interference with LH activity. Labhsetwar (1966) advocated that MPA blocked primarily the synthesis and only secondarily the release of LH. His conclusions were based on experiments in which immature rats were injected with $12.5 \mathrm{mg}$ MPA twice a week for 5 weeks. Conclusions based on such an experimental model may not necessarily apply to other experimental models. Banik \& Herr (1969) assumed that MPA blocked LH release. This is also my assumption for the following reason. By the time the MPA affected the hypothalamo-pituitary axis, the pituitary probably contained sufficient LH to cause ovulation, if release was permitted. Since ovulation did not occur, it is conjectured that LH release was blocked. To decide whether LH release, LH synthesis, or both were blocked, it would be necessary to quantify pituitary and plasma LH. The possibility that MPA may also interfere with FSH activity cannot be ruled out.

Normally, the surge of LH release occurs between 14.00 and 16.00 hours (the 'critical time') on the day of pro-oestrus, and injecting barbiturates at, or slightly before, 14.00 hours blocks the release of LH (Everett \& Sawyer, 1950). Apparently these agents work very rapidly. On the other hand, MPA took much longer to block LH: when injected $4 \mathrm{hr}$ before the onset of the 'critical time' (i.e. at 10.00 hours), a block was not achieved. The reasons for the absence of an effect could be that (1) MPA is slow to reach the target organ, (2) once at the target organ, it may take considerable time to precipitate the block, and (3) the specific area where the block occurs may be different in MPA-treated as compared with barbiturate-treated rats.

Depo-MPA has been used as a long-term contraceptive by injecting patients intramuscularly with 150 to $1000 \mathrm{mg}$ MPA once every 3 to 6 months (Tyler, 1968; Zanartu, 1968; Soichet, 1969). The presumed mode of action is blockage of ovulation. In women so treated, fertility is usually re-established 6 to 18 months after the last injection. Babies born to treated mothers appeared normal (Zanartu, 1968). In principle, the present study showed similar results for the rat: a single injection of MPA blocked cyclicity for a relatively long period of time; when cycles recurred, their lengths were frequently irregular and the first cycle in most cases was infertile; the offspring of treated mothers showed no abnormalities. 


\section{ACKNOWLEDGMENTS}

This study was supported in part by the Population Council and the Ford Foundation. The technical assistance of $\mathrm{Mr} \mathrm{J}$. R. Hart and the typing of the manuscript by Mrs Judy Childs are gratefully acknowledged.

\section{REFERENCES}

BANIK, U. K., HALTRECHT, I. \& HERR, F. (1970) Induction of ovulation in progestin-treated adult rats. Acta endocr., Copenh. 63, 747.

BANIK, U. K. \& HERR, F. (1969) Effects of medroxyprogesterone acetate and chlorpromazine on ovulation and vaginal cytology in a strain of 4-day cyclic rats. Can. F. Physiol. Pharmacol. 47, 573.

EvereTt, J. W. \& SAWYER, G. H. (1950) A 24-hour periodicity in the "LH-release apparatus" of female rats, disclosed by barbiturate sedation. Endocrinology, 47, 198.

LABHSETWAR, A. P. (1966) Mechanism of action of medroxyprogesterone (17 $\alpha$-acetoxy- $6 \alpha$-methyl progesterone) in the rat. 7. Reprod. Fert. 12, 445.

SoIchet, S. (1969) Depo-Provera (medroxyprogesterone acetate) as a female contraceptive agent. Int. F. Fert. 14, 33.

TyLer, E. T. (1968) Current studies in contraception: the use of a long-acting progesterone by injection. S. Afr. med. 7. 42, 257.

ZANARTU, J. (1968) Long-term contraceptive effect of injectable progestogens inhibition and restablishment of fertility. Int. J. Fert. 13, 415. 